\title{
Insecticide Susceptibility Status of Aedes albopictus in Dengue Hotspot Areas in Malaysia
}

\author{
Wan Fatma Zuharah ${ }^{1,2}$, Ahmad Mohiddin ${ }^{1}$, Asmalia Md Lasim ${ }^{1}$ and Zairi Jaal² \\ ${ }^{1}$ Medical Entomology Laboratory, School of Biological Sciences, Universiti Sains Malaysia, Penang 11800, Malaysia \\ ${ }^{2}$ Vector Control Research Unit, Universiti Sains Malaysia, Penang 11800, Malaysia
}

\begin{abstract}
The vector control program has become challenging due to the resistance problem occurs in Aedes mosquitoes. Aedes albopictus (Skuse, 1894) is the most dominant species contributing as a vector of dengue, Chikungunya and Zika viruses in Malaysia. Knowledge of the current insecticide resistance of $A e$. albopictus is essential for the success of vector control program. Here, we reported the susceptibility status of Ae. albopictus collected from the dengue hotspot areas in the Northern District of Penang Island, Malaysia on three common use insecticides in vector control program. Aedes albopictus was sampled from three localities at Flat Hamna, Kampung Sungai Gelugor and Kampung Tanjung Tokong in the Northern District of Penang Island, Malaysia. The adult bioassay results suggested the Flat Hamna strain (FH) was found to develop incipient resistance after $24 \mathrm{~h}$ exposure towards all three insecticides tested; permethrin, deltamethrin and malathion (mortality 97-87\%). With 1.93 fold of Resistance Ratio $50\left(R_{50}\right)$ values, FH strains have the highest chances to develop resistance towards permethrin. Among all insecticides tested, malathion was contributed to significantly higher $\mathrm{KdT}_{50} \mathrm{O}$ in all Ae. albopictus strains as compared to VCRU reference strain $(\mathrm{p}<0.001)$. Thus suggesting malathion insecticide is the least effective insecticide in our vector control program. Our finding can be used as a baseline for insecticide resistance of Ae. albopictus to improve vector control across Malaysia. Permethrin and deltamethrin are still reliable to be used in the control program, nonetheless require continuous monitoring on their susceptibility towards Ae. albopictus.
\end{abstract}

Keywords: Aedes; chemical control; dengue; insecticide; mosquito; resistance; susceptibility

\section{INTRODUCTION}

Aedes aegypti and Aedes albopictus are two main important vectors for the transmission of dengue viruses (DENV), Chikungunya virus (CHIKV) and latest with reemergence of Zika virus (ZIKV) which risk million global population life (Muso \& Gubler, 2016). In Malaysia, the transmission of dengue fever is mainly caused Aedes aegypti as a principal vector, while Ae. albopictus is a secondary vector (Smith, 1956). Dengue being endemic in Malaysia, spread irrespective of the urbanization level. Both of these species are day-biters and share the same behavioural attributes (Chuaycharoensuk et al., 2011).

Hence, there is still no promising vaccine for DENV, CHIKV and ZIKV, a control program for both vector species is essential to prevent an outbreak (Chuaycharoensuk et. al., 2011; Polsomboon et. al., 2008; Kamgang et al., 2011) with attention to eliminate breeding sites and larval habitats via source reduction. However, the existing permanent breeding sites cannot easily be accessed (Chuaycharoensuk et. al., 2011; Gomez et al., 2011) to reduce the mosquito populations. To prevent the spread of dengue, especially during a dengue outbreak still relies on the insecticide usage (Montella et. al., 2007; Ocampo et al., 2011). Three major pyrethroid class mainly selected in to control Aedes species through cold or thermal spraying in vector control programs is permethrin, deltamethrin and cypermethrin (Teng \& Singh, 2001).

However, the massive use of insecticides has lead to the resistance problem in Aedes mosquitoes. Resistance decreases the susceptibility of vectors to insecticide and 
defines as the ability of the insect to tolerate the dosage of insecticides that could kill the majority of individuals in a population (WHO, 1960). Ever since the first discovery of insecticide resistance in mosquitoes in the late 1940s (Brown, 1986), there were increasing concerns and research efforts in understanding the resistance development in mosquitoes. The failures in vector borne disease control programs, especially during epidemic outbreaks are mainly driven by resistance problem (Marcombe et al., 2012). The evolution of insecticide resistance has been linked to the failure of dengue control activities and continuous use of certain insecticide has led to faster resistance in mosquitoes. Increasing resistance among mosquitoes also related to the exposure to chemicals in agriculture programs and other activities that use synthetic chemicals (Nazni et al., 2005; Overgaard, 2006). The first incident of mosquito resistance was recorded in 1947 against DDT (Baber, 1958) on Culex pipiens (Linnaeus) in Italy (Mosna, 1947) and Aedes solicitans (Walker) in Florida (Brown, 1986). Afterwards, Ae. aegypti has been recorded to become resistant towards pyrethroids (Mebrahtu et. al., 1997; Macoris et. al., 2007; Rong et al., 2012).

Despite the increasing advances in alternative strategies in vector control, chemical controls remain as the fundamental tool in suppressing mosquito population during the epidemic period. However, more than 100 species of mosquitoes are reported to have developed resistance towards one or more insecticides, with more than 50 species of these are from the genus Culicinae (WHO, 1992). Resistance towards pyrethroids, in particular, leads to significant operational failure of Ae. aegypti control and subsequently, the increased transmission of the disease (Amelia-Yap et al., 2018).

Therefore, we evaluate the current susceptibility status of commonly used insecticide by the Health Department of Penang Island in vector control program on Aedes albopictus from the dengue hotspot areas of the northern district of Penang Island.

\section{MATERIALS AND METHOD}

\section{A. Mosquitoes}

Three wild strains of Ae. albopictus mosquitoes were collected randomly from three localities which has been known as dengue hotspot areas in Flat Hamna $\left(\mathrm{FH}-5^{\circ} 2 \mathrm{O}^{\prime} \mathrm{N}\right.$, $\left.100^{\circ} 17^{\prime} \mathrm{E}\right)$, Kampung Sungai Gelugor (KSG- $\left.5^{\circ} 21^{\prime} \mathrm{N}, 100^{\circ} 18^{\prime} \mathrm{E}\right)$ and Kampung Tanjung Tokong (KTT- $5^{\circ} 27^{\prime} \mathrm{N}, 100^{\circ} 18^{\prime} \mathrm{E}$ ), Penang Island, Malaysia (Figure 1). These three areas reported a high number of confirmed dengue cases every year and frequently treated with insecticides for vector control program. Wild strain mosquitoes were collected from natural breeding sites, such as tires, discarded tins, cans and flower pots. While, Aedes albopictus VCRU susceptible strains were used as a mosquito reference baseline for susceptibility test to permethrin, deltamethrin, and malathion was provided by the Vector Control Unit, Universiti Sains Malaysia $\left(5^{\circ} 21^{\prime} \mathrm{N}\right.$, $\left.100^{\circ} 18^{\prime} \mathrm{E}\right)$. The VCRU mosquito strain has been cultured in the laboratory since the 1970 s for more than 800 generations.

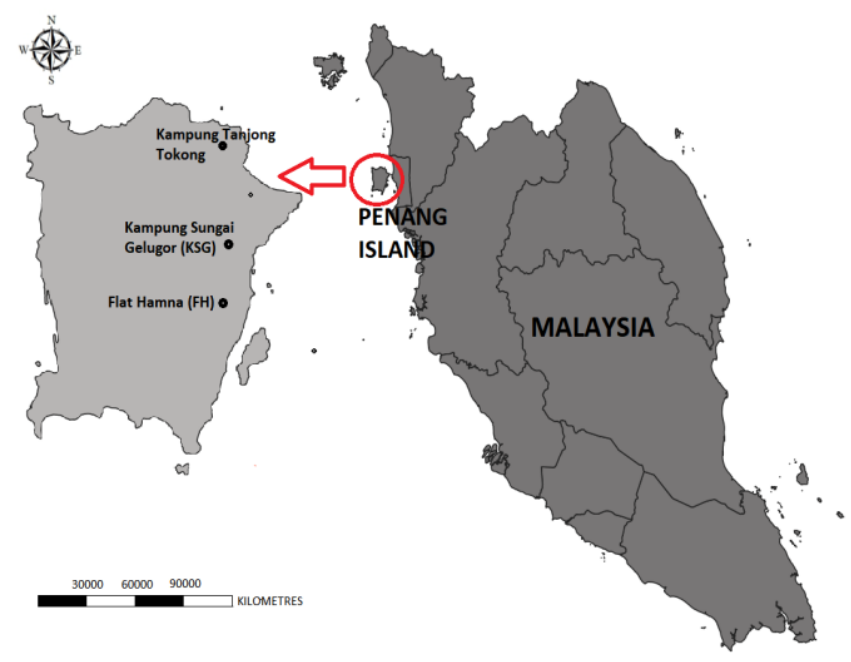

Figure 1. Aedes albopictus sampling sites at the Northern District Penang Island, Malaysia

Larvae and pupae of Aedes albopictus wild strain were identified, colonized and cultured until adults in the laboratory at a temperature of $26 \pm 2^{\circ} \mathrm{C}$ and $70-80 \%$ of $\mathrm{RH}$. The larvae were fed with 10mg of larval food daily made of cat biscuits, beef liver, yeast and milk at a ratio of 2:1:1:1 by weight. At two to five days old, adult female mosquitoes were offered blood fed from mice confined in mesh wire to obtain the eggs. Blood fed adult female mosquitoes were then provided with $10 \%$ sucrose containing B-complex vitamin. A moist cone shape filter paper was provided as an oviposition substrate for egg laying. The optimum number of eggs was collected over three to four days, and the eggs were allowed to hatch in the seasoned water and reared to adult. 


\section{B. WHO Adult Bioassay Test Procedure}

The non-blood fed female of Ae. albopictus from $\mathrm{F}_{1}$ generation aged two to five days old was used for bioassay test according to WHO standard procedures for insecticide resistance testing (WHO, 1998). However, in certain cases, $\mathrm{F}_{2}$ generation was used due to an insufficient number of $F_{1}$ progeny. Whatman paper sized $12 \mathrm{~cm}$ x $15 \mathrm{~cm}$ were impregnated separately with $2 \mathrm{ml}$ of diagnostic dose of $0.75 \%$ of permethrin, $0.05 \%$ deltamethrin or $5 \%$ malathion. Olive oil was used for OP control and silicone oil for pyrethroid control. The impregnated paper was air-dried or three days and stored in $4^{\circ} \mathrm{C}$ until used.

A total of 20 non-blood fed female mosquitoes per tube were introduced into each holding tube during the bioassay test. Mosquitoes were given one hour of acclimation time and any dead or abnormal mosquitoes were replaced with a new individual. Each set of impregnated paper with a concentration of $0.75 \%$ of permethrin, $0.05 \%$ deltamethrin or $5 \%$ malathion was placed into the test tube separately. The mosquitoes from the holding tube were then transferred into the test tube containing treated impregnated paper. Knockdown data were recorded every five minutes for an interval of one hour. After the exposure period, all of the mosquitoes were transferred to the $300 \mathrm{ml}$ paper cup covered with muslin cloth and mosquitoes were provided with $10 \%$ sucrose. The mortality rate was observed after 24h. All experiments were run separately and each was replicated 15 times for each strain.

\section{Data Analysis}

Percentage of mortality after the $24 \mathrm{~h}$ exposure to insecticides in the adult bioassay test was characterized for the susceptibility status using WHO criteria where mosquitoes are considered as: (1) susceptible, if the percentage mortality was between 98 and 100\%, (2) incipient resistant if mortality was $80-98 \%$ and (3) resistant if mortality was <80\% (WHO, 1998). The mortality data were log-transformed subjected to ANOVA analysis to determine the differences between strains. To obtain knockdown time $50 \quad\left(\operatorname{KdT}_{50}\right)$ and knockdown time $95\left(\mathrm{KdT}_{95}\right)$, all of the data were analyzed using a Probit analysis in SPSS version 20.0. Data were logtransformed prior to the statistical analysis to fulfil the

assumption of the Probit analysis. $\mathrm{KdT}_{50}$ was defined as the time required to knock down $50 \%$ of the mosquitoes (Ocampo et al., 2011), whereas KdT95 was the time required for 95\% knockdown of mosquitoes. The value of $\mathrm{KdT}_{50}$ and $\mathrm{KdT}_{95}$ was analyzed using ANOVA in order to compare the susceptibility of insecticides of the wild field mosquito population from different localities. Based on the $\mathrm{KdT}_{50}$ and $\mathrm{KdT}_{95}$, the values of the resistance ratio (RR) were determined by dividing the knockdown time of the wild field strain to the knockdown time of the susceptible strain. The mosquito population was considered susceptible $(\mathrm{RR}<3)$, low resistance $(3<\mathrm{RR}<5)$, moderate resistance $(5<\mathrm{RR}<10)$ and high resistance $(\mathrm{RR}$ $>10$ ) (Mazzarri \& Georghiou, 1995).

\section{RESULT}

After 24 hours Ae. albopictus were exposed to insecticides, population in Flat Hamna (FH) was detected performed incipient resistance to permethrin, deltamethrin and malathion for Flat with given mortality of $93 \%$, $97 \%$ and $87 \%$, respectively (Table 1). Thus, it indicated that the FH strain started to develop resistance towards insecticides that used in a vector control program. Incipient resistance towards permethrin also detected in KSG strain (mortality 96\%) but not in KTT strain (100\%). Whereas, both strains KSG and KTT are still susceptible to deltamethrin and malathion (100\%). The significant difference in adult mortality between localities was only detected in malathion with the highest mortality (87\%) occurred in FH strain (ANOVA, F=13.72, $\mathrm{df}=3, \mathrm{p}<0.05$; Table 1). VCRU strain (control) confirmed its susceptibility status as reference strains in the adult bioassay test with $100 \%$ mortality for all insecticides. No mortality was found in mosquitoes treated in control set of OP and silicone oil. 
Table 1. Resistance status of Aedes albopictus female adults from Flat Hamna, Kampung Sungai Gelugor and Kampung Tanjung Tokong strain to permethrin, deltamethrin and malathion after 24 hours exposure

\begin{tabular}{|c|c|c|c|c|c|c|}
\hline \multirow[b]{2}{*}{ Strain } & \multicolumn{2}{|c|}{$\begin{array}{c}0.75 \% \\
\text { Permethrin }\end{array}$} & \multicolumn{2}{|c|}{$\begin{array}{c}0.05 \% \\
\text { Deltamethrin }\end{array}$} & \multicolumn{2}{|c|}{$\begin{array}{c}5 \% \\
\text { Malathion }\end{array}$} \\
\hline & $\begin{array}{c}\text { Mortality } \\
\text { (\%) }\end{array}$ & Status & $\begin{array}{c}\text { Mortality } \\
\text { (\%) }\end{array}$ & Status & $\begin{array}{c}\text { Mortality } \\
\text { (\%) }\end{array}$ & Status \\
\hline VCRU Susceptible & $100^{\mathrm{a}}$ & $\mathrm{S}$ & $100^{\mathrm{a}}$ & $\mathrm{S}$ & $100^{\mathrm{a}}$ & $\mathrm{S}$ \\
\hline Flat Hamna (FH) & $93^{\mathrm{a}}$ & IR & $97^{a}$ & IR & $87^{\mathrm{b}}$ & IR \\
\hline $\begin{array}{l}\text { Kampung Sungai } \\
\text { Gelugor (KSG) }\end{array}$ & $96^{a}$ & IR & $100^{\mathrm{a}}$ & $\mathrm{S}$ & $100^{\mathrm{a}}$ & $\mathrm{S}$ \\
\hline $\begin{array}{l}\text { Kampung Tanjung } \\
\text { Tokong (KTT) }\end{array}$ & $100^{a}$ & $\mathrm{~S}$ & $100^{a}$ & S & $100^{a}$ & $\mathrm{~S}$ \\
\hline
\end{tabular}

All $\mathrm{KdT}_{50}$ for all of the Ae. albopictus strains were found significantly higher than VCRU reference strain ( $\mathrm{p}<0.05$; Figure 2). The significantly higher $\mathrm{KdT}_{50}$ (43.27 min) and $\mathrm{KdT}_{95}(68.71 \mathrm{~min})$ was recorded for malathion in $\mathrm{FH} A e$. albopictus population to the VCRU resistance strains $\left(\mathrm{KdT}_{950}\right.$ $\mathrm{F}=27.18, \mathrm{df}=3, \mathrm{p}<0.001 ; \mathrm{KdT}_{95} \mathrm{~F}=21.39, \mathrm{df}=3, \mathrm{p}<0.001 ;$ no overlapping of CIs).

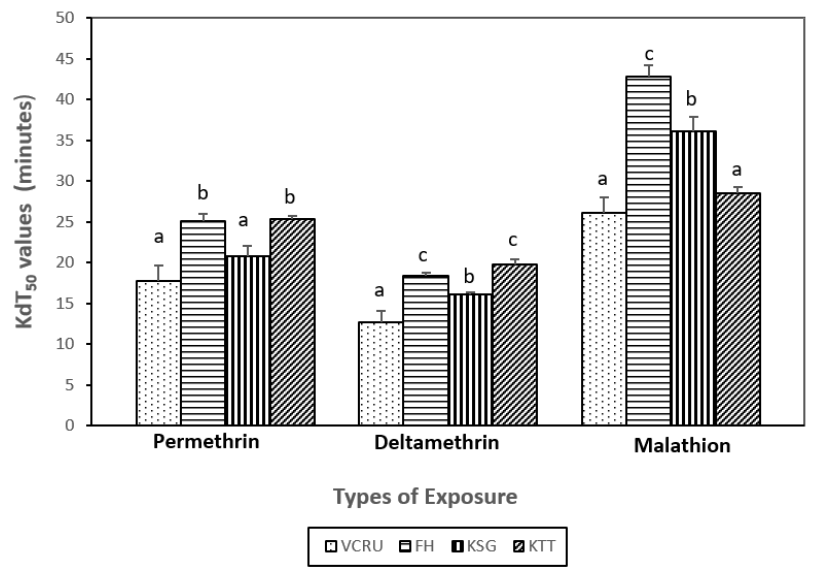

Figure 2. Comparative $\mathrm{KdT}_{50}$ values for three strains of Aedes albopictus after an hour exposure to permethrin, deltamethrin and malathion using the adult bioassay technique

The Aedes albopictus in the $\mathrm{FH}$ strains treated with malathion insecticide had the $\mathrm{RR}_{95}$, at 1.68 -fold, but this still considers within the susceptible value (Table 2). The same Ae. albopictus population from $\mathrm{FH}$ localities showed the significantly highest value of $\mathrm{KdT}_{95}$ (51.57 min) with 1.93-fold towards permethrin. Surprisingly, Ae. albopictus population from KTT exposed to deltamethrin showed significantly slower $\mathrm{KdT}_{50}$ (20.05 min, 1.53-fold) and $\mathrm{KdT}_{95}$ (42.26 min, 1.87 -fold) compared to other populations $\left(\mathrm{KdT}_{950} \mathrm{~F}=27.98\right.$, $\mathrm{df}=3, \mathrm{p}<0.001 ; \mathrm{KdT}_{95} \mathrm{~F}=17.07, \mathrm{df}=3, \mathrm{p}<0.001 ;$ Table 2), even though the $24 \mathrm{~h}$ resistance status was recorded as susceptible with 100\% mortality (Table 1).

Table 2. Knockdown time (KdT) and resistance ratio (RR) of Aedes albopictus from different localities to the organophosphates and pyrethroid insecticides after an hour exposure

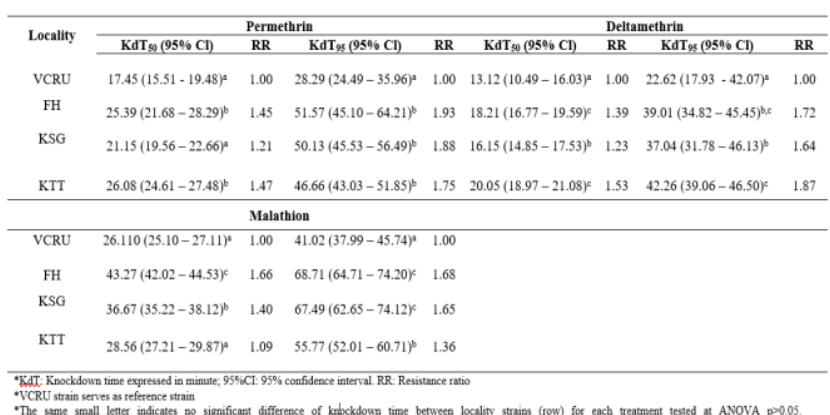

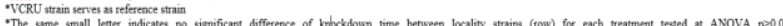

\section{DISCUSSION}

We found that all of Ae. albopictus sample collected from the hotspot dengue areas is still susceptible towards all three commonly used insecticides in Malaysia; permethrin, deltamethrin and malathion based on resistance ratio values. However, Ae. albopictus population from Flat Hamna (FH) started to develop incipient resistance to all permethrin, deltamethrin and malathion. Given that the malathion diagnostic dose was at $5 \%$, which is the highest dose among all insecticide dosages, malathion is considered the least effective insecticide. In Malaysia, malathion has been used since 1960 for dengue vector control to control the Aedes populations during the dengue outbreak in Penang, Malaysia for thermal fogging, Ultra Low Volume (ULV) fogging and in agricultural sites (Muda, 1985). In addition, the usage of malathion was stopped in 1996 and replaced with a pyrethroid water-based solution product (Teng \& Singh, 2001). The pyrethroid products use in vector control program in Malaysia is Aqua Resigen (a.i; permethrin (25/75): 10.11\% w/w, s-bioallethrin: $0.14 \%$ w/w, piperonyl butoxide: $9.96 \%$ w/w) and Resigen (a.i; permethrin (25/75): 18.7\% w/w, sbioallethrin: $0.8 \% \mathrm{w} / \mathrm{w}$, piperonyl butoxide: $16.8 \% \mathrm{w} / \mathrm{w}$ ), which are manufactured by Bayer Co. (Malaysia) Sdn. Bhd. In 2005, the application of malathion is adapted again in the vector control program due to its effectiveness and efficiency to control Aedes populations (VBDC, 2004). The same 
malathion insecticide has been used in Jaffna, Sri Lanka (Surendran et al., 2007; Pimsamarn et al., 2009) in their vector control program and also Brazil have utilized it since 1999 (Macoris et al., 2007).

Even, the resistance ratio value indicates susceptibility, but two strains of Ae. albopictus from FH and KSG exhibited slight incipient resistance towards $0.75 \%$ permethrin after 24h exposure. Similar findings from the Shah Alam, Selangor Ae. albopictus strain indicated low mortality with an RR value of 2.1 (Rong et al., 2012). In 2011, the Ae. albopictus strain from the same Flat Hamna, Sungai Dua, Penang locality exhibited resistance ratio of 0.98 for permethrin and 1.19 for deltamethrin (Chan et al., 2011). Our study found that the resistance ratio for permethrin and deltamethrin have increased to 1.45 for permethrin and 1.19 for deltamethrin. In which, the risk towards resistance in permethrin increases by $47.96 \%$ within three years and $16.81 \%$ for deltamethrin. Once dengue cases are reported in all of the dengue cases areas, action is taken in the infected areas and treatment will be begin with the thermal fog using Aqua Resigen (Bayer Co. (Malaysia) Sdn. Bhd), Pesguard FG 161 (Agricultural Chemicals (M) Sdn. Bhd). Resigen and Pesguard products which classified under pyrethroid class. Similar vector control management has been applied in both areas of Flat Hamna and Kampung Sungai Gelugor when dengue cases were reported. Whereas, ULV has normally been used for emergency control of Aedes in urban areas (Kawada et al., 2009). Since the resistance becomes an issue in effectiveness for controlling Aedes population in dengue hotspot areas, the Department of Health Penang has monitored and evaluated the use of thermal fogging and ULV activities, as well as the effect of this insecticide on resistance. The authority is now scheduling a morning ULV trip to cover all localities. The Aedes survey also has been done according to the schedule and the area is fogged once the density of Aedes mosquitoes exceeded the sensitivity limit of the Aedes Index (AI) at $>1 \%$.

Deltamethrin at $0.05 \%$ dose is still considered as an effective means of control for Ae. albopictus population at the moment for all three dengue hotspot areas. But, the study by Ishak et al., (2016) found that the sibling species, Ae. aegypti collected from Bayan Baru, Penang was found resistance towards permethrin and deltamethrin. A study in Surabaya and Palembang found that the mosquitos are still susceptible to deltamethrin (Intan et al., 2006). This is similar to the study in Central Africa, Vietnam (North and Center strains) and Southern Thailand which found that Ae. albopictus populations are still susceptible to pemethrin and deltamethrin (Jirakanjanakit et al., 2007). However, in Yaounde, the mosquitoes had incipient resistance towards deltamethrin with $83.3 \%$ mortality rate (Kamgang et al., 2011).

The same standard mosquito control management techniques were applied at these three study sites with the fogging activities was carried out twice in 14 days after dengue case is reported. During the outbreak, the fogging activities were conducted every three days until the outbreak was over. Flat Hamna $(\mathrm{FH})$ is known to be the most prevalent dengue hotspot area and had the highest frequency of vector control activity, followed by Kampung Sungai Gelugor and Kampung Tanjung Tokong. This was in response to the potential and reported number of dengue cases. Therefore, more frequent fogging was conducted caused the Aedes population increasingly exposed to the insecticide and may increase the mosquitoes' tolerance towards the resistance mechanism in selected areas. The intensity of selection may decline if the mosquitoes are occasionally or routinely exposed to the insecticide that brings an advantage to the resistance (Komalamisra et al., 2003).

There were two main alterations in the resistance mechanisms of the target site, as well as an increased rate of insecticide detoxification (Serrano, 2012). Insects will increase the production of monooxygenases, nonspecific esterase, and GST, as well as reduces the sensitivity of sodium channel in neuron membranes (Flores et. al., 2009; Pimsamarn et al., 2009). In Malaysia, kdr mutation of F1534C and V1016G were detected in Ae. aegypti with signatures of selection were detected on the Voltage-gated sodium channel gene, but not in Ae. albopictus (Ishak et al., 2016). The study in the northeast province of Thailand on permethrin and deltamethrin found that monooxygenase, glutathione-S-tranferase (GSTs) and esterase have a tendency to increase in the Bora Bora mosquito strain and are associated with a genetic cost in the absence of selection. In turn, this causes other forms of resistance to create mechanisms apart from the increased enzyme in order to detoxify the aforementioned insecticide toxin (Pimsamarn et 
al., 2009). The Surabaya mosquito strain also responded to the pyrethroid insecticide by significantly increasing the enzyme activities and presuming the cooperation of the enzyme in detoxifying the pyrethroid entering the insect (Intan et al., 2006). This situation may occur due to selection by certain insecticides on one or more genes that generally extend to other compounds sharing the same target sites (Selvi et al., 2005). Aedes aegypti in Bangkok were also found to be resistant towards deltamethrin and permethrin with significantly higher levels of activities related to nonspecific esterase and GSTs (Pethuan et al., 2007). The addition of PBO synergist in the insecticides was suggested to cause metabolic resistance in both Aedes species (Ishak et al., 2016).

The pattern of insecticide resistance may vary among localities and it is very important to adopt a new strategy of surveillance for dengue control management. Households and agriculture have used higher amounts of insecticides (Huong et al., 2004). This may accelerate resistance, making it quicker and more severe than our expectation. The tolerance of Ae. albopictus to insecticides shows that they will develop full resistance in the future and this will become a major problem in vector control programs. Therefore, entomological risk assessments are one of the important factors of a successful insecticide management strategy. In addition to the assessment of resistance status, the types of insecticide used, the impact of the insecticide (Reiter \& Nanthan, 2011), the type of vector habitat (Esu et al., 2010), geographical variation in rainfall, temperature and land coverage can influence the density of the mosquito population (Abeyewickreme et al., 2012). Regular resistance surveillance of mosquitoes should be focused on areas with a high level of dengue fever transmission and intensive usage of insecticides.

\section{CONCLUSION}

Our finding concludes that the Ae. albopictus of Flat Hamna strain from which area frequently reported dengue cases has started to develop incipient resistance towards all insecticides used in vector control program. In which, the highest chances to develop resistance is towards permethrin. Whereas, malathion was found less effective insecticides and possibly related to the frequency of fogging activity in this high dengue cases areas. Continuous monitoring on the current susceptibility status of Ae. albopictus is necessary especially in dengue hotspot areas and finding new control methods such as integrated vector management (IVM) using combination techinque between biological and chemical controls should be the focus on near future.

\section{ACKNOWLEDGEMENT}

This project was funded under the The Fundamental Research Grant Scheme, The Ministry of Higher Education Malaysia (203/PBIOLOGI/6711629) and Reseach Universitiy Grant under Universiti Sains Malaysia (1001/PBIOLOGI/8011066). We would like to acknowledge the Director of Health Malaysia for the permission to publish this paper. Also the Director of Penang Health Department and Vector-Borne Disease Control Program of Penang for all the support and technical assistance. We are grateful to the volunteer from all study site resident for their active participation.

\section{REFERENCES}

Abeyewickreme, W, Wickramasinghe, AR, Karunatilake, K, Sommerfeld, J \& Axel, K 2012, 'Community mobilization and household level waste management for dengue vector control in Gampaha district of Sri Lanka; an intervention study', Pathog Glob Health, vol. 106, no. 8, 479-487.

Amelia-Yap, ZH, Chen, CD, Sofian-Azirun, M \& Low, VL 2018, 'Pyrethroid resistance in the dengue vector Aedes aegypti in Southeast Asia: present situation and prospects for management', Parasites \& Vectors, vol. 11, no. 1, pp. 332
Baber, FH 1958, 'Biochemistry and physiology of resistance by insects to insecticides', Indian J Malariology, vol. 12, no. 4, pp. 517-529.

Brown, AW 1986, 'Insecticide resistance in mosquito, a pragmatic review', Journal of the American Mosquito Control Association, vol. 2, pp. 123-140.

Chan, HH, Mustafa, FW \& Zairi, J 2011, 'Assessing the susceptibility status of Aedes albopictus on Penang Island 
using two different assays', Trop Biomed, vol. 28, no. 2, pp. 464-470.

Chuaycharoensuk, T, Juntarajumnong, W, Boonyuan, W, Bangs, MJ, Akratanakul, P, Thammapalo, S, Jirakanjanakit, N, Tanasinchayakul, S \& Chareoniviriyaphap, T 2011, 'Frequency of pyrethroid resistance in Aedes aegypti and Aedes albopictus (Diptera; Culicidae) in Thailand', J Vector Ecol, vol. 36, no. 1, pp. 204-212.

Esu, E, Lenhart, A, Smith, L \& Horstick, O 2010, 'Effectiveness of periodomestic space spraying with insecticide on dengue transmission; systematic review', Trop Med Int Health, vol. 15, no. 5, pp. 619-631.

Flores, AE, Solis, GR, Salas, IF, Francisco, J, Ramos, S \& Garcia, GP 2009, 'Resistance to permethrin in Aedes aegypti (L.) in Northern Mexico', Southwestern Entomol, vol. 34, no. 2, pp. 167-177.

Gomez, A, Seccacini, E, Zerba, E \& Licastro, S 2011, 'Comparison of the insecticide susceptibilities of laboratory strains of Aedes aegypti and Aedes albopictus', Mem Inst Oswaldo Cruz, vol. 106, no. 8, pp. 993-996.

Huong, VD, Ngoc, NTB, Hein, DT \& Lien, NTB 2004, 'Susceptibility of Aedes aegypti to insecticide in Viet Nam', Dengue Bull, vol. 28, pp. 179-183.

Intan, A, Astari, S, Rohardjo, B, Tan, M \& Munif, A 2006, 'Resistance of Aedes aegypti from three province in Indonesia to pyrethroid and organophosphate insecticide' International Conference on Mathematic and Natural Science (ICMNS), pp. 226-229.

Ishak, IH, Jaal, Z, Ranson, H \& Wondji, CS 2016, 'Contrasting patterns of insecticide resistance and knockdown resistance (kdr) in the dengue vectors Aedes aegypti and Aedes albopictus from Malaysia', Parasit Vectors, vol. 25, no. 8, pp. 181.

Jirakanjanakit, N, Rongnoparut, P, Saengtharatip, S, Chareomviriyaphap, T, Duchon, S, Bellec, C \& Yoksan, S 2007, 'Insecticide susceptible/resistance status in Aedes (Stegomyia) aegypti and Aedes (Stegomyia) albopictus (Diptera, Culicidae) in Thailand during 2003-2005', J Econ Entomol, vol. 100, no. 2, pp. 545-550.

Kamgang, B, Marcombe, S, Chandre, F, Nchoutpouen, E, Nwane, P, Etang, J, Corbel, V \& Paupy, C 2011, 'Insecticide susceptibility of Aedes aegypti and Aedes albopictus in Central Africa', Parasit Vectors, vol. 4, pp. 79.

Kawada, H, Higa, Y, Nguyen, YT, Tran, SH, Nguyen, HT \& Takagi, M 2019, 'Nationwide investigation of the pyrethroid susceptibility of mosquito larvae collected from used tires in Vietnam', PLoS Negl Trop Dis, vol. 3, no. 3, pp. e391.
Komalamisra, N, Pant, SK, Apiwathnasorn, C, Choochote, W \& Rongsriyam, Y 2002, 'Pyrethroid resistance in association with the used of insecticide impregnated bed nets', J Trop Med Parasitol, vol. 26, pp. 62-67.

Macoris, MDLDG, Andrighetti, MTM, Otreta, VCG, Carvalho, LRD, Caldas, AL \& Brogdon, WG 2007, 'Association of insecticide use and alteration on Aedes aegypti susceptibility status', Mem Inst Oswaldo Cruz, vol. 102, no. 8, pp. 895-900.

Marcombe, S, Mathieu, RB, Pocquet, N, Riaz MA, Poupardin R, Selior S, Darriet F, Reynaud S, Yebakima, A, Corbel, V, David, JP \& Chandre, F 2012, 'Insecticide resistance in dengue vector Aedes aegypti from Martinique, distribution, mechanisms and relations with environmental factors', PLos ONE, vol. 7, no. 2, pp. e30989.

Mazzarri, MB \& Georghiou, GP 1995, 'Characterization of resistance to organoohosphate, carbamate and pyrethroid insecticide in field population of Aedes aegypti from Venezuela', J Am Mosq Control Assoc, vol. 11, pp. 315-322.

Mebrahtu, YB, Norem, J \& Taylor, M 1997, 'Inheritance of larval resistance to permethrin in Aedes aegypti and association with sex ratio distortion and life history variation', Am J Trop Med Hyg, vol. 56, pp. 456-465.

Montella, IR, Martins, AJ, Vianna-Medeiros, PF, Lima, JBP, Braga, IA \& Valle, D 2017, 'Insecticide resistance mechanism of Brazilian Aedes aegypti population from 2001 to 2004', Am J Trop Med Hyg, vol. 77, no. 3, pp. 467477.

Mosna, E 1947, 'Su una caratteristica biologica del Culex pipiens autogenicus di Latina', Riv Parassit, vol. 8, pp. 125126.

Muda, AR 1985, 'Pest problem and the use of pesticide in grain storage in Malaysia', Australian Centre for Agricultural Research, Australia, pp. 11-16.

Muso, D \& Gubler, DJ 2016, 'Zika virus', Clinical Microbiology Review, vol. 29, no. 3, pp. 487-524.

Nazni, WA, Lee, HL \& Azahari, AH 2005, 'Adult and larval insecticide susceptibility status of Culex quinquefasciatus (Say) mosquitoes in Kuala Lumpur Malaysia', Trop Biomed, vol. 22, no. 1, pp. 63-68.

Ocampo, CB, SalazarTerreros, MJ, Mina, NJ, McAllister, J \& Brogdon, W 2011, 'Insecticide resistance status of Aedes aegypti in 10 localities in Columbi', Acta Tropica, vol. 118, pp. 37-44.

Overgaard, HJ 2006, 'Malaria mosquitoes resistance to agricultural insecticide, risk area mapping in Thailand, 
Colombo, and Sri Lanka', International Water Management Institute, Sri Lanka, pp. 68.

Pethuan, S, Jirakanjanakit, N, Saengtharatio, S, Chareonviriyaphap, T, Kaewpa, D \& Rongnoparut, P 2007, 'Biochemical studies of insecticide resistance in Aedes (Stegomyia) aegypti and Aedes (Stegomyia) albopictus (Diptera, Culicidae) in Thailand', Trop Biomed, vol. 24, no. 1, pp. 7-15.

Pimsamarn, S, Sompeng, W, Akksilp, S, Paeporn, P \& Limpawitthayakul, M 2019, 'Detection of insecticide resistance in Aedes aegypti to organophosphate and synthetic pyrethroid compound in the Northeast of Thailand', Dengue Bull, vol. 33, pp. 194-202.

Polsomboon, S, Grieco, JP, Achee, NL, Chauhan, KR, Tanasinchayakul, S, Pothikasikorn, J \& Chareonviriyaphap, $\mathrm{T}$ 2008, 'Behavioral responses of catnip (Nepeta cataria) by two species of mosquitoes, Aedes aegypti and Anopheles harrisoni, in Thailand', Journal of the American Mosquito Control Association, vol. 24, no. 4, pp. 513-519.

Reiter, P \& Nanthan, MB 2011, 'Guidelines for assessing the efficacy of insecticidal space sprays for control of dengue vector Aedes aegypti, Dengue Bull, vol. 25, 122 WHO/CDS/CPE/PVC/2001.1.

Rong, LA, Andy, TWA, Nazni, WA, Lee, HL \& Sofian-Azirun, M 2012, 'Insecticide susceptibility status of field collected Aedes (Stegomyia) aegypti (L.) at a dengue endemic site in Shah Alam, Selangor Malaysia', Southeast Asian J Trop Med Public Health, vol. 43, no. 1, pp. 34-47.

Selvi, S, Edah, MA, Nazni, WA, Lee, HL \& Azahari, AH 2005, 'Resistance development and insecticide susceptibility in Culex quenquefasciatus against selection pressure of malathion and permethrin and its relationship to crossresistance towards propoxur', Trop Biomed, vol. 22, no. 2, pp. 103-113.

Serrano, RM 2012, 'Susceptibility status of Aedes aegypti to insecticide in Columbia' in Perveen F. Insecticide- Pest Engineering. Intechopen, Croatia, pp. 163-200.

Smith, CE 1956, 'The history of dengue in tropical Asia and its probable relationship to the mosquito Aedes aegypti, Journal of Tropical Medicine and Hygiene, vol. 59, pp. 243251.

Surendran, SN, Kajatheepan, A, Sanjeefkumar, KFA \& Jude, PJ 2007, 'Seasonality and insecticide susceptibility of dengue vevtor, an ovitrap based survey in a residential area of Northern Sri Lanka', Southeast Asian Journal of Tropical Medicine and Public Health, vol. 38, no. 2, pp. 276-282.
Teng, AK \& Singh, S 2001, 'Epidemiology and new initiatives in the prevention and control of dengue in Malaysia', Dengue Bull, vol. 25, pp. 7-14.

VBDC 2014, 'Penggunaan racun serangga organophosphate dalam kawalan wabak denggi', Kuala Lumpur, VBDC Bil.(69)204/250/1 Jld.I.

World Health Organization 1960, 'Insecticide resistance and vector control', World Health Organization Technical Report Series, Geneva, no. 191, pp. 6.

World Health Organization 1992, 'Vector resistance to pesticides', Fifteenth report of the expert committee on vector biology and control, in WHO Technical report series, vol. 818, pp. 1-55.

World Health Organization 2016, 'Test procedures for insecticide resistance monitoring in malaria vectors', 2nd edn, World Health Organization, Geneva, pp. 56. 